\title{
Ability of traditional lipid ratios and apolipoprotein ratios to predict cardiovascular risk in people with type 2 diabetes
}

\author{
M.-R. Taskinen • P. J. Barter • C. Ehnholm • \\ D. R. Sullivan • K. Mann • J. Simes • J. D. Best • \\ S. Hamwood • A. C. Keech • \\ on behalf of the FIELD study investigators
}

Received: 24 February 2010 / Accepted: 22 April 2010/Published online: 6 June 2010

(C) Springer-Verlag 2010

\begin{abstract}
Aims/hypothesis The apolipoprotein B (ApoB):apolipoprotein A (ApoA)-I ratio may be a better indicator of cardiovascular disease (CVD) risk in people with type 2 diabetes than traditional lipid risk markers (LDL-cholesterol, HDL-

Electronic supplementary material The online version of this article (doi:10.1007/s00125-010-1806-9) contains supplementary material, which is available to authorised users.
\end{abstract}

\section{M.-R. Taskinen $(\bowtie)$}

Department of Medicine, Division of Cardiology,

Helsinki University Central Hospital,

Biomedicum, Haartmaninkatu 8,

00029 Helsinki, Finland

e-mail: Marja-Riitta.Taskinen@helsinki.fi

\section{P. J. Barter}

Heart Research Institute, University of Sydney,

Sydney, NSW, Australia

C. Ehnholm

Department of Molecular Medicine,

National Public Health Institute,

Biomedicum,

Helsinki, Finland

D. R. Sullivan

Department of Clinical Biochemistry,

Royal Prince Alfred Hospital,

Sydney, NSW, Australia

K. Mann $\cdot$ J. Simes $\cdot$ A. C. Keech

National Health and Medical Research Council Clinical Trials

Centre, University of Sydney,

Sydney, NSW, Australia

\section{J. D. Best}

School of Medicine, University of Melbourne,

Melbourne, VIC, Australia

\section{S. Hamwood}

Department of Medicine, Nambour General Hospital,

Nambour, QLD, Australia cholesterol and triacylglycerol), but whether the ApoB: ApoA-I ratio should be used to indicate lipid-lowering therapy is still debated.

Methods The Fenofibrate Intervention and Event Lowering in Diabetes (FIELD) study randomised 9,795 patients with type 2 diabetes to fenofibrate ( $200 \mathrm{mg}$ daily) or placebo and followed them up for a median of 5 years. We compared ApoB, ApoA-I, ApoAII and the ApoB:ApoA-I ratio with traditional lipid variables as predictors of CVD risk. We estimated the HR of the effect of 1 SD difference in baseline concentrations of lipids, apolipoproteins and respective ratios on the risk of CVD events and also used receiver operating characteristic curve analysis.

Results In the placebo group, the variables best predicting CVD events were non-HDL-cholesterol:HDL-cholesterol, total cholesterol:HDL-cholesterol (HR 1.21, $p<0.001$ for both), ApoB:ApoA-I (HR 1.20, $p<0.001$ ), LDL-cholesterol:HDLcholesterol (HR 1.17, $p<0.001$ ), HDL-cholesterol (HR 0.84, $p<0.001$ ) and ApoA-I (HR 0.85, $p<0.001$ ). In the fenofibrate group, the first four predictors were very similar (but ApoB: ApoA-I was fourth), followed by non-HDL-cholesterol and ApoB. Lipid ratios and ApoB:ApoA-I performed better than any single lipid or apolipoprotein in predicting CVD risk.

Conclusions/interpretation In patients with type 2 diabetes in the FIELD study, traditional lipid ratios were as strong as the ApoB:ApoA-I ratio in predicting CVD risk. The data provide little evidence for replacement of traditional lipids and their ratios with measures of ApoB, ApoA-I and their ratio.

Keywords Cardiovascular risk - Diagnostic tests - Lipids . Lipoproteins · Non-HDL-cholesterol · Type 2 diabetes

\author{
Abbreviations \\ ApoA Apolipoprotein A \\ ApoB Apolipoprotein B \\ CARDS Collaborative Atorvastatin Diabetes Study
}




$\begin{array}{ll}\text { CVD } & \text { Cardiovascular disease } \\ \text { ERFC } & \text { Emerging Risk Factors Collaboration } \\ \text { FIELD } & \begin{array}{l}\text { Fenofibrate Intervention and Event Lowering } \\ \text { in Diabetes }\end{array} \\ \text { ROC } & \begin{array}{l}\text { Receiver operating characteristic } \\ \text { TRL }\end{array} \\ \text { Triacylglycerol-rich lipoproteins }\end{array}$

\section{Introduction}

Atherosclerotic cardiovascular disease (CVD) results from the interplay of genetic and environmental factors. The new epidemic of type 2 diabetes and the dyslipidaemia associated with it is fuelling an alarming wave of premature CVD. Diabetic dyslipidaemia is a cluster of lipid and apolipoprotein abnormalities, which include elevated triacylglycerol-rich lipoproteins (TRLs), an excess of small dense LDL particles (independent of the concentration of LDL-cholesterol) and reduced concentrations of both HDLcholesterol and the major HDL apolipoprotein, apolipoprotein A (ApoA)-I $[1,2]$.

There is evidence that the number of TRL and LDL particles (as distinct from concentrations of the triacylglycerol and cholesterol transported by them) is a major determinant of cardiovascular risk [3-6]. As TRL and LDL particles contain a single molecule of apolipoprotein $B$ (ApoB), the concentration of $\mathrm{ApoB}$ in plasma provides a measure of the concentration of all potentially atherogenic lipoproteins and thus may be a better indicator of cardiovascular risk than the simple measurement of LDLcholesterol [7-10]. This may be particularly important for people with type 2 diabetes, who tend to have increased concentrations of atherogenic TRL and small LDL particles, such that the LDL-cholesterol concentration no longer reflects the particle concentration of $\operatorname{LDL}[1,11]$.

Another measure of the concentration of all potentially atherogenic lipoproteins is the level of non-HDLcholesterol, as determined by subtracting the concentration of cholesterol in HDL from that in total plasma [12]. There is growing evidence that the concentration of non-HDLcholesterol is superior to LDL-cholesterol as a predictor of future cardiovascular events [13-16]. As a consequence, non-HDL-cholesterol has been introduced into many guidelines as a secondary target for therapy in people with elevated serum triacylglycerols, even if they have achieved recommended LDL goals [17-21]. The question of whether non-HDL-cholesterol has the same predictive power as $\mathrm{ApoB}$ is a debated issue $[7,12,15,22,23]$. One recent study suggested that concentrations of non-HDLcholesterol and ApoB are virtually identical in terms of their ability to predict cardiovascular events [24].
The other common lipid abnormality in people with type 2 diabetes is a low level of potentially protective HDL particles, whether measured as HDL-cholesterol or as ApoA-I $[1,2]$. People with type 2 diabetes have a double problem: (1) a high particle concentration of atherogenic lipoproteins (TRL and LDL); and (2) a low concentration of HDL particles [25]. Measurements that may capture this combined problem include ratios of total to HDLcholesterol, non-HDL-cholesterol to HDL-cholesterol, LDL-cholesterol to HDL-cholesterol and ApoB to ApoA-I [16, 17, 19, 26-29]. The ApoB:ApoA-I ratio was superior to traditional lipid and apolipoprotein levels as a predictor of CVD in large case-control studies (the Interheart study and the Apolipoprotein-Related Mortality Risk study) [30, 31] and in people treated with statins [32]. These analyses have fuelled recommendations that routine assessment of ApoB and ApoA-I should replace measurements of the standard lipids, particularly in people with diabetes [3335]. It is uncertain, however, whether the ApoB:ApoA-I ratio is superior to lipid ratios such as total cholesterol: HDL-cholesterol, non-HDL-cholesterol:HDL-cholesterol or LDL-cholesterol:HDL-cholesterol. The Emerging Risk Factors Collaboration (ERFC) group analysed 68 studies including more than 300,000 people and found comparable HRs for the non-HDL-cholesterol:HDL-cholesterol and ApoB:ApoA-I ratios [36]. The Collaborative Atorvastatin Diabetes Study (CARDS) investigators reported that the ApoB:ApoA-I ratio was only marginally superior to that of LDL-cholesterol:HDL-cholesterol in predicting cardiovascular events in people with type 2 diabetes [37].

In this study we evaluated the performance of a range of lipid and apolipoprotein concentrations, including ApoA-II, as well as relevant ratios (expanding the ERFC data), in predicting cardiovascular risk in 9,795 patients with type 2 diabetes from the Fenofibrate Intervention and Event Lowering in Diabetes (FIELD) study (International Standard Randomised Controlled Trial registration no. ISRCT64783481) [38].

\section{Methods}

Participants The FIELD participants have been described in detail elsewhere [38]. Briefly, type 2 diabetic patients aged 50 to 75 years were eligible if they had an initial plasma total cholesterol concentration of 3.0 to $6.5 \mathrm{mmol} / \mathrm{l}$ and a total cholesterol:HDL-cholesterol ratio of 4.0 or higher, or a plasma triacylglycerol concentration of 1.0 to $5.0 \mathrm{mmol} / \mathrm{l}$, without requiring lipid-modifying treatment at study entry. Significant renal impairment (plasma creatinine $>130 \mu \mathrm{mol} / \mathrm{l}$ ), chronic liver disease, symptomatic gallbladder disease or a cardiovascular event within 3 months of recruitment were exclusion criteria. 
All patients provided written informed consent and the study protocol was approved by local and national ethics committees in accordance with the Declaration of Helsinki and Good Clinical Practice guidelines.

Procedures We randomly assigned 9,795 patients to micronised fenofibrate $200 \mathrm{mg}$ once daily (Laboratoires Fournier, Dijon, France) or matching placebo. Patients were followed up at 4- to 6-month intervals for a median of 5 years while receiving routine care from their usual healthcare professionals. Total cholesterol, HDL-cholesterol, triacylglycerol, ApoB, ApoA-I and ApoA-II were measured at baseline and at study end (Fig. 1). All blood samples were analysed in one of two central laboratories in Adelaide, Australia or Helsinki, Finland. The laboratories participated in national quality assurance schemes for all analytes and were aligned for lipid and $\mathrm{HbA}_{1 \mathrm{c}}$ analyses through the Canadian External Quality Assurance Laboratory in Vancouver. Methods used to measure lipids were accredited by the Centers for Disease Control Lipid Standardization Program.

The pre-specified outcome for subgroup studies and the outcome used in this secondary study was total cardiovascular events, a term comprising coronary heart disease death, cardiovascular death, non-fatal myocardial infarction, stroke and coronary or carotid revascularisation. All events were adjudicated by an outcomes assessment committee blinded to treatment allocation.

Statistical analysis All analyses were performed on an intention-to-treat basis. Variables of interest were total cholesterol, LDL-cholesterol, HDL-cholesterol, triacylglycerol, ApoB, ApoA-I and the following Apo and lipid ratios: total cholesterol:HDL-cholesterol, LDL-cholesterol: HDL-cholesterol, non-HDL-cholesterol:HDL-cholesterol and ApoB:ApoA-I. The effect of one SD increment in these variables on total cardiovascular events was assessed

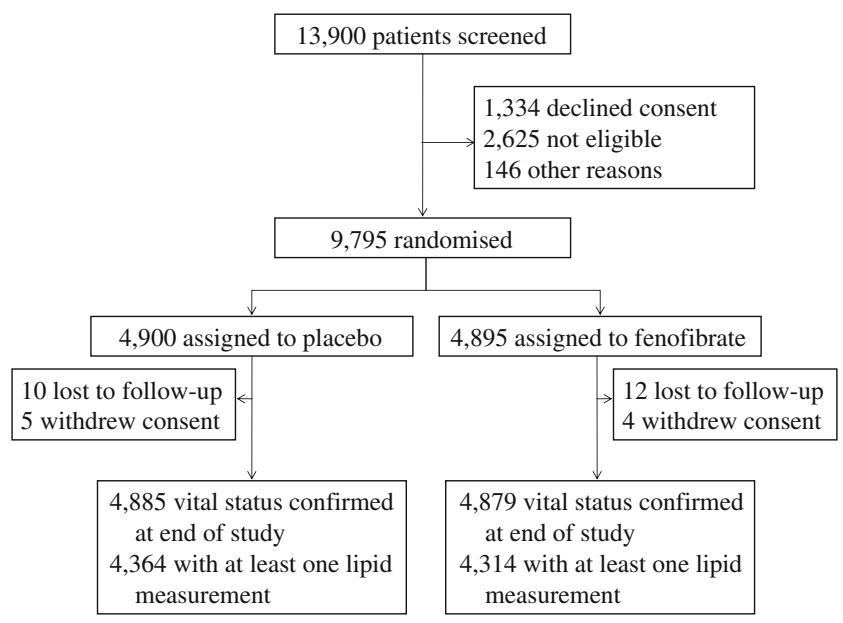

Fig. 1 Enrolment and progress of patients in the FIELD trial by HRs and 95\% CIs in univariate Cox proportional hazards analyses. Adjusted multivariate analyses followed; these included the variable or ratio of interest adjusted for treatment, age, sex, prior myocardial infarction, prior coronary artery bypass graft surgery, smoking status, insulin use, $\mathrm{HbA}_{1 \mathrm{c}}$, creatinine and country of residence. The strengths of association among the variables were ranked by the two statistics. The proportional hazards assumptions were met in all models. The $p$ value is a measure of strength of the association between the treatment and the lipid variable based on the likelihood-ratio test. The $p$ value for interaction was based on the Wald test of the interaction term from an adjusted model with the lipid variable or ratio of interest, treatment and the corresponding interaction term.

In addition, the relationships between quartiles of baseline lipid variable or ratios and HRs for cardiovascular risk were assessed by Cox proportional hazards analysis using the first quartile as the reference level.

The degree of predictability of cardiovascular risk for the lipids and ratios of interest was compared by receiver operating characteristic (ROC) curve analysis. This logistic regression model had the individual cardiovascular endpoint (binary data) as the dependent variable and the lipid or apolipoprotein variables or ratios of interest (continuous) as the predictor variable. Each patient was classified as a case or control, and various cut-off points were applied to the predicted probability obtained from the logistic regression. The true positive rate (sensitivity) and false positive rate (specificity) were calculated on the basis of observed versus expected values. The AUC was calculated by integrating the area between the ROC curve and the diagonal line (where sensitivity is equal to 1 -specificity) based on the trapezoidal rule [39]. These AUC curves were produced for all patients and then for each treatment group.

All statistical analyses used a two-sided significance of 0.05 and were performed with SAS (version 9.2; SAS Institute, Cary, NC, USA).

\section{Results}

The baseline characteristics of the study cohort are given in Table 1. The placebo and fenofibrate groups were well matched for clinical history, medication and baseline concentrations and ratios of lipids and apolipoproteins. At study close (Table 2), the concentrations of HDLcholesterol, ApoA-I and ApoA-II were all significantly higher in the fenofibrate than in the placebo group, the change being most marked for ApoA-II (27.2\%). The concentrations of LDL-cholesterol and ApoB, and the total cholesterol:HDL-cholesterol, LDL-cholesterol:HDL-cholesterol, non-HDL-cholesterol:HDL-cholesterol and ApoB: 
Table 1 Baseline characteristics and medication per group

\begin{tabular}{|c|c|c|}
\hline Characteristic & Placebo & Fenofibrate \\
\hline$n$ & 4,900 & 4,895 \\
\hline \multicolumn{3}{|l|}{ General characteristics } \\
\hline Men $(\%)$ & 63 & 63 \\
\hline Age at visit 1 (years) & $62(7)$ & $62(7)$ \\
\hline Duration of diabetes (years) & $5(2-10)$ & $5(2-10)$ \\
\hline \multicolumn{3}{|l|}{ Clinical history } \\
\hline Previous CVD (\%) & 22 & 22 \\
\hline History of hypertension (\%) & 56 & 57 \\
\hline Current or ex-smoker $(\%)$ & 60 & 60 \\
\hline \multicolumn{3}{|l|}{ Laboratory data: lipids and lipoproteins } \\
\hline \multicolumn{3}{|l|}{ Atherogenic } \\
\hline Triacylglycerol (mmol/l) & $1.73(1.34-2.30)$ & $1.74(1.35-2.34)$ \\
\hline Total cholesterol (mmol/l) & $5.03(0.71)$ & $5.04(0.69)$ \\
\hline LDL-cholesterol (mmol/l) & $3.07(0.66)$ & $3.07(0.64)$ \\
\hline ApoB $(g / 1)$ & $0.97(0.17)$ & $0.97(0.17)$ \\
\hline Non-HDL-cholesterol (mmol/l) & $3.94(0.69)$ & $3.95(0.68)$ \\
\hline \multicolumn{3}{|l|}{ Anti-atherogenic } \\
\hline HDL-cholesterol (mmol/l) & $1.10(0.26)$ & $1.10(0.26)$ \\
\hline ApoA-I (g/l) & $1.29(0.21)$ & $1.29(0.21)$ \\
\hline ApoA-II (g/l) & $0.35(0.07)$ & $0.35(0.07)$ \\
\hline \multicolumn{3}{|l|}{ Ratios } \\
\hline Total cholesterol:HDL-cholesterol & $4.80(1.10)$ & $4.81(1.10)$ \\
\hline Non-HDL-cholesterol:HDL-cholesterol & $3.78(1.10)$ & $3.80(1.09)$ \\
\hline LDL-cholesterol:HDL-cholesterol & $2.92(0.84)$ & $2.93(0.82)$ \\
\hline ApoB:ApoA-I & $0.77(0.18)$ & $0.77(0.18)$ \\
\hline \multicolumn{3}{|l|}{ Other laboratory data } \\
\hline $\mathrm{HbA}_{1 \mathrm{c}}$ & $6.9(6.1-7.8)$ & $6.9(6.1-7.8)$ \\
\hline Plasma creatinine $(\mu \mathrm{mol} / \mathrm{l})$ & $77(16)$ & $78(16)$ \\
\hline Homocysteine $(\mu \mathrm{mol} / \mathrm{l})$ & $9.6(8.0-11.4)$ & $9.5(7.9-11.6)$ \\
\hline Microalbuminuria (\%) & 25 & 26 \\
\hline
\end{tabular}

Unless otherwise indicated, values are mean (SD) or median (interquartile range) in the fenofibrate group, but not in the placebo group. Again, the interaction tests were not significant $(p=0.28$ and $p=0.14$, respectively).

All lipid ratios and the ApoB:ApoA-I ratio were significantly associated with cardiovascular outcomes in both groups (Table 3$)$. The likelihood ratio statistics $\left(\chi^{2}\right)$ were of approximately the same magnitude for non-HDLcholesterol:HDL-cholesterol, total cholesterol:HDL-cholesterol, LDL-cholesterol:HDL-cholesterol and ApoB:ApoA-I ratios. In terms of their ability to predict cardiovascular events, these lipid and ApoB:ApoA-I ratios performed better overall than any of the individual lipid or apolipoprotein concentrations in both groups. There was no indication that ApoB:ApoA-I ratio was superior to any of the lipid ratios.

The predictive performance of different variables for cardiovascular outcomes in the two groups was also evaluated using ROC curve analysis (Fig. 2). As judged by the area under the ROC curve, performance was equal for concentrations of HDL-cholesterol and ApoA-I, which cholesterol and LDL-cholesterol were separately predictive 
Table 2 Lipids and lipoproteins at study close and percentage changes from baseline

\begin{tabular}{|c|c|c|c|c|c|c|c|c|}
\hline \multirow[t]{2}{*}{ Variable } & \multicolumn{3}{|c|}{ Fenofibrate group } & \multicolumn{3}{|c|}{ Placebo group } & \multicolumn{2}{|l|}{ Difference } \\
\hline & $\begin{array}{l}\text { Relative } \\
\text { change }(\%)^{\mathrm{a}}\end{array}$ & $95 \% \mathrm{CI}$ & $p$ value $^{\mathrm{b}}$ & $\begin{array}{l}\text { Relative } \\
\text { change }(\%)^{\mathrm{a}}\end{array}$ & $95 \% \mathrm{CI}$ & $p$ value $^{\mathrm{b}}$ & $\begin{array}{l}\text { In relative } \\
\text { change }(\%)\end{array}$ & $p$ value \\
\hline Triacylglycerol (mmol/l) & -25.8 & $-26.7,-24.9$ & $<0.001$ & -4.7 & $-5.8,-3.6$ & $<0.001$ & -21.1 & $<0.001$ \\
\hline Total cholesterol $(\mathrm{mmol} / \mathrm{l})$ & -16.8 & $-17.2,-16.33$ & $<0.001$ & -10.4 & $-11.0,-9.9$ & $<0.001$ & -6.4 & $<0.001$ \\
\hline LDL-cholesterol (mmol/1) & -22.2 & $-22.8,-21.5$ & $<0.001$ & -17.7 & $-18.5,-16.9$ & $<0.001$ & -4.5 & $<0.001$ \\
\hline ApoB $(g / l)$ & -17.7 & $-18.3,-17.1$ & $<0.001$ & -10.9 & $-11.6,-10.2$ & $<0.001$ & -6.9 & $<0.001$ \\
\hline $\begin{array}{l}\text { Non-HDL-cholesterol } \\
(\mathrm{mmol} / \mathrm{l})\end{array}$ & -22.8 & $-23.3,-22.2$ & $<0.001$ & -14.3 & $-14.9,-13.6$ & $<0.001$ & -8.5 & $<0.001$ \\
\hline HDL-cholesterol $(\mathrm{mmol} / \mathrm{l})$ & 1.9 & $1.3,2.5$ & $<0.001$ & 1.4 & $0.9,1.9$ & $<0.001$ & 0.6 & 0.14 \\
\hline ApoA-I (g/l) & 1.6 & $1.1,2.2$ & $<0.001$ & 0.0 & $-0.4,0.5$ & 0.89 & 1.6 & $<0.001$ \\
\hline ApoA-II (g/l) & 25.9 & $25.0,26.8$ & $<0.001$ & -1.3 & $-1.9,-0.7$ & $<0.001$ & 27.2 & $<0.001$ \\
\hline $\begin{array}{l}\text { Total cholesterol: } \\
\text { HDL-cholesterol }\end{array}$ & -18.5 & $-19.1,-18.0$ & $<0.001$ & -11.8 & $-12.5,-11.2$ & $<0.001$ & -6.7 & $<0.001$ \\
\hline $\begin{array}{l}\text { LDL-cholesterol: } \\
\text { HDL-cholesterol }\end{array}$ & -23.8 & $-24.5,-23.0$ & $<0.001$ & -18.9 & $-19.8,-18.0$ & $<0.001$ & -4.9 & $<0.001$ \\
\hline $\begin{array}{l}\text { Non-HDL-cholesterol: } \\
\text { HDL-cholesterol }\end{array}$ & -24.3 & $-25.0,-23.5$ & $<0.001$ & -15.4 & $-16.2,-14.6$ & $<0.001$ & -8.9 & $<0.001$ \\
\hline ApoB:ApoA-I & -19.0 & $-19.7,-18.3$ & $<0.001$ & -10.9 & $-11.7,-10.1$ & $<0.001$ & -8.1 & $<0.001$ \\
\hline
\end{tabular}

${ }^{a}$ Relative changes between baseline and close-out were calculated for each variable using geometric means based on log-transformation of data; analyses were based on 4,289-4,367 patients in the placebo group and 4,244-4,314 patients in the fenofibrate group

${ }^{\mathrm{b}}$ For comparison of baseline and close data in each treatment arm (paired data)

were superior to total cholesterol and ApoB in both groups. The performance of total cholesterol:HDL-cholesterol, nonHDL-cholesterol:HDL-cholesterol, LDL-cholesterol:HDLcholesterol and ApoB:ApoA-I ratios was also similar in the two groups. Analyses were repeated for each treatment group separately, with similar results (data not shown).

The prediction of cardiovascular outcomes by lipid and ratio quartiles is shown in Table 4. The HR for cardiovascular

Table 3 Hazard ratios and $\chi^{2}$ (likelihood ratio test) for total CVD events for one SD increment in lipid or lipid ratio variables at baseline

\begin{tabular}{|c|c|c|c|c|c|c|c|c|}
\hline \multirow[t]{2}{*}{ Variable $^{\mathrm{a}, \mathrm{b}}$} & \multicolumn{4}{|c|}{ Placebo group ${ }^{c}$} & \multicolumn{4}{|c|}{ Fenofibrate group } \\
\hline & HR & $95 \% \mathrm{CI}$ & $\chi^{2}$ & $p$ value & HR & $95 \% \mathrm{CI}$ & $\chi^{2}$ & $p$ value \\
\hline Non-HDL-cholesterol:HDL-cholesterol & 1.21 & $1.12-1.31$ & 24.0 & $<0.001$ & 1.28 & $1.18-1.39$ & 36.2 & $<0.001$ \\
\hline Total cholesterol:HDL-cholesterol & 1.21 & $1.12-1.31$ & 23.7 & $<0.001$ & 1.28 & $1.18-1.39$ & 35.8 & $<0.001$ \\
\hline ApoB:ApoA-I & 1.20 & $1.12-1.30$ & 23.1 & $<0.001$ & 1.25 & $1.16-1.36$ & 31.2 & $<0.001$ \\
\hline LDL-cholesterol:HDL-cholesterol & 1.17 & $1.09-1.27$ & 16.8 & $<0.001$ & 1.29 & $1.19-1.40$ & 36.2 & $<0.001$ \\
\hline HDL-cholesterol & 0.84 & $0.76-0.91$ & 15.9 & $<0.001$ & 0.83 & $0.76-0.92$ & 14.3 & $<0.001$ \\
\hline ApoA-I & 0.85 & $0.78-0.93$ & 14.0 & $<0.001$ & 0.87 & $0.79-0.95$ & 9.2 & 0.002 \\
\hline ApoB & 1.14 & $1.05-1.23$ & 11.1 & 0.001 & 1.22 & $1.12-1.32$ & 22.3 & $<0.001$ \\
\hline Non-HDL-cholesterol & 1.13 & $1.04-1.22$ & 8.9 & 0.003 & 1.23 & $1.13-1.33$ & 23.8 & $<0.001$ \\
\hline Triacylglycerol $^{\mathrm{d}}$ & 1.07 & $1.00-1.15$ & 3.2 & 0.07 & 1.06 & $0.98-1.15$ & 1.8 & 0.18 \\
\hline Total cholesterol & 1.06 & $0.98-1.15$ & 2.4 & 0.12 & 1.16 & $1.07-1.26$ & 12.3 & $<0.001$ \\
\hline LDL-cholesterol & 1.05 & $0.98-1.14$ & 1.8 & 0.18 & 1.16 & $1.07-1.26$ & 12.9 & $<0.001$ \\
\hline ApoA-II & 0.96 & $0.88-1.04$ & 1.1 & 0.29 & 0.91 & $0.83-1.00$ & 4.3 & 0.04 \\
\hline
\end{tabular}

${ }^{a}$ There were no significant interactions between HR and treatment group

${ }^{\mathrm{b}}$ Adjusted for sex, age, prior myocardial infarction, prior coronary artery bypass grafting, smoking, creatinine concentration, insulin use, HbA $\mathrm{A}_{\mathrm{c}}$ and country of residence

${ }^{\mathrm{c}}$ Values by $\chi^{2}$ rank in placebo group

${ }^{\mathrm{d}}$ Additionally adjusted for HDL-cholesterol 

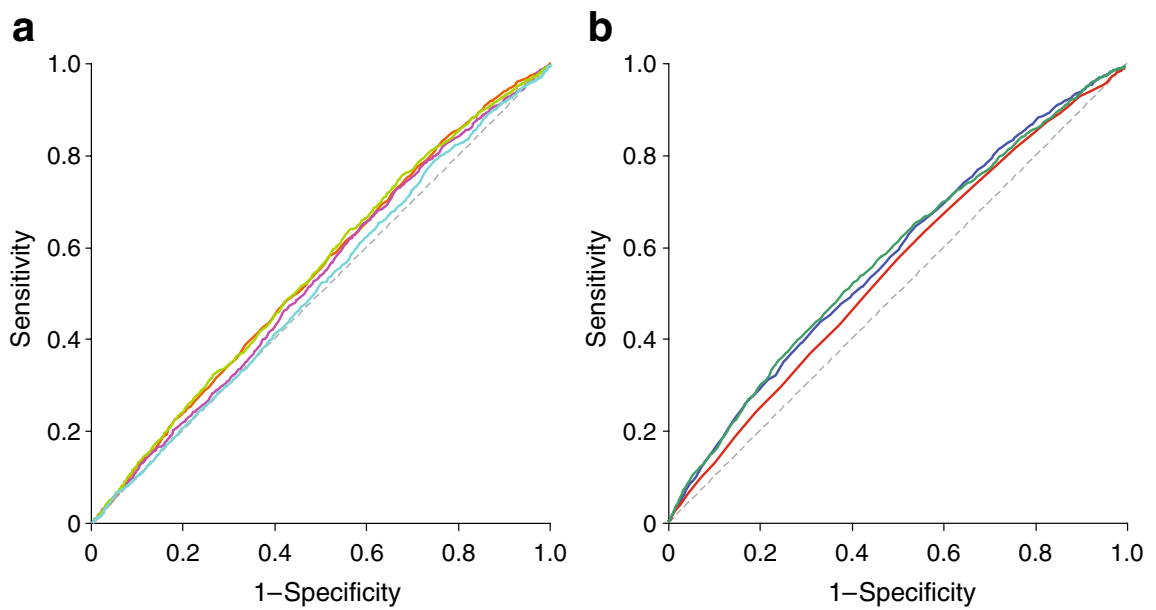

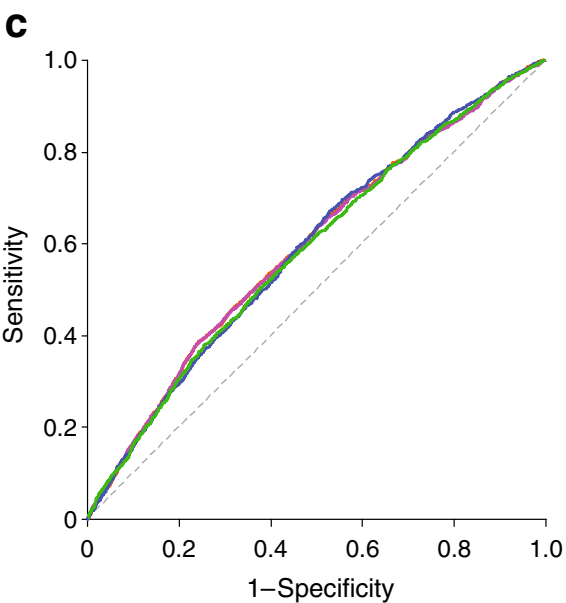

Fig. 2 Receiver operating characteristic curves with AUCs and 95\% CIs for (a) atherogenic and (b) protective lipids and lipoproteins, and (c) lipid and lipoprotein ratios. a Green line, non-HDL-cholesterol (0.547 [0.531-0.564]); orange line, ApoB (0.545 [0.528-0.561]); pink line, LDL-cholesterol (0.530 [0.513-0.546]); blue line, total cholesterol $(0.516$ [0.500-0.533]); (b) green line, HDL-cholesterol $(0.580$
[0.564-0.597]); blue line, ApoA-I (0.578 [0.562-0.595]); red line, ApoA-II (0.551 [0.534-0.567]); (c) green line, LDL-cholesterol:HDLcholesterol (0.585 [0.568-0.601]); blue line, ApoB:ApoA-I (0.589 [0.572-0.605]); orange line, total cholesterol:HDL-cholesterol $(0.592$ [0.575-0.608]); pink line, non-HDL-cholesterol:HDL-cholesterol $(0.592[0.575-0.608])$

Cox proportional hazards models and by ROC curve analysis for different variables.

Diabetic dyslipidaemia is characterised by a high concentration of potentially atherogenic TRLs and small, dense LDL particles in combination with a low concentration of potentially anti-atherogenic HDL particles. Notably, in the FIELD and the Action to Control Cardiovascular Risk in Diabetes studies the event rates were higher in participants with marked dyslipidaemia (triacylglycerol $>2.3 \mathrm{mmol} / \mathrm{l}$ and low HDL-cholesterol) than in those without [43, 44], although in FIELD the groups were not heterogeneous. Consequently, ratios that take account of the levels of atherogenic and anti-atherogenic lipoproteins have been recommended as an effective way to estimate cardiovascular risk in people with type 2 diabetes. In the CARDS study (2,350 participants with type 2 diabetes), the ratios at baseline of ApoB:ApoA-I and LDL-cholesterol: HDL-cholesterol were superior to measurements of either lipid fraction or apolipoprotein alone in terms of predicting cardiovascular events in people with diabetes [37]. The authors of that report concluded (as do we from this analysis of the FIELD study) that, in clinical practice, the measurement of the ApoB:ApoA-I ratio has little to offer over the ratio of LDL-cholesterol:HDL-cholesterol. In the current analysis of diabetic patients in the FIELD study, we also found that the HR for the ApoB:ApoA-I ratio was virtually identical to that for the total cholesterol:HDLcholesterol and non-HDL-cholesterol:HDL-cholesterol ratios, but little better than that for the LDL-cholesterol:HDLcholesterol ratio. This observation is fully consistent with results from the ERFC study reporting comparable HRs for non-HDL-cholesterol:HDL-cholesterol, total cholesterol: fenofibrate groups as assessed by computing HRs from 
Table 4 Effect of lipid ratios and baseline levels on cardiovascular events, by quartiles

\begin{tabular}{|c|c|c|c|c|c|}
\hline \multirow[t]{2}{*}{ Variables in ranges } & \multirow[t]{2}{*}{ CVD event rate } & \multicolumn{2}{|l|}{ Unadjusted } & \multicolumn{2}{|l|}{ Adjusted $^{\mathrm{a}}$} \\
\hline & & $\operatorname{HR}(95 \% \mathrm{CI})$ & $p$ value & $\operatorname{HR}(95 \% \mathrm{CI})$ & $p$ value \\
\hline \multicolumn{6}{|c|}{ Lipid and lipoprotein } \\
\hline \multicolumn{6}{|c|}{ Triacylglycerol $(\mathrm{mmol} / \mathrm{l})^{\mathrm{b}}$} \\
\hline$<1.34$ & 2.9 & 1 & & 1 & \\
\hline $1.34-1.73$ & 3.0 & $1.02(0.86-1.20)$ & 0.84 & $1.02(0.91-1.26)$ & 0.81 \\
\hline $1.74-2.33$ & 3.5 & $1.19(1.01-1.39)$ & 0.03 & $1.15(0.98-1.36)$ & 0.08 \\
\hline$>2.33$ & 3.8 & $1.32(1.13-1.53)$ & $<0.001$ & $1.17(0.99-1.39)$ & 0.06 \\
\hline \multicolumn{6}{|c|}{ Total cholesterol (mmol/1) } \\
\hline$<4.56$ & 2.8 & 1 & & 1 & \\
\hline $4.56-5.03$ & 3.6 & $1.29(1.10-1.51)$ & 0.002 & $1.33(1.14-1.56)$ & $<0.001$ \\
\hline $5.04-5.54$ & 3.5 & $1.26(1.07-1.47)$ & 0.005 & $1.37(1.17-1.61)$ & $<0.001$ \\
\hline$>5.54$ & 3.4 & $1.21(1.03-1.42)$ & 0.02 & $1.41(1.19-1.66)$ & $<0.001$ \\
\hline \multicolumn{6}{|c|}{ LDL-cholesterol (mmol/l) } \\
\hline$<2.63$ & 2.7 & 1 & & 1 & \\
\hline $2.63-3.08$ & 3.5 & $1.30(1.10-1.52)$ & $<0.002$ & $1.28(1.09-1.51)$ & 0.002 \\
\hline $3.09-3.52$ & 3.6 & $1.35(1.15-1.59)$ & $<0.001$ & $1.34(1.14-1.57)$ & $<0.001$ \\
\hline$>3.52$ & 3.4 & $1.27(1.08-1.50)$ & 0.003 & $1.31(1.11-1.54)$ & 0.002 \\
\hline \multicolumn{6}{|c|}{ Non-HDL-cholesterol (mmol/1) } \\
\hline$<3.47$ & 2.5 & 1 & & 1 & \\
\hline $3.47-3.93$ & 3.5 & $1.42(1.21-1.68)$ & $<0.001$ & $1.39(1.17-1.63)$ & $<0.001$ \\
\hline $3.94-4.40$ & 3.4 & $1.38(1.17-1.63)$ & $<0.001$ & $1.42(1.20-1.68)$ & $<0.001$ \\
\hline$>4.40$ & 3.9 & $1.59(1.35-1.87)$ & $<0.001$ & $1.65(1.40-1.95)$ & $<0.001$ \\
\hline \multicolumn{6}{|l|}{ ApoB (g/l) } \\
\hline$<0.86$ & 2.6 & 1 & & 1 & \\
\hline $0.86-0.97$ & 3.6 & $1.34(1.14-1.57)$ & $<0.001$ & $1.35(1.15-1.59)$ & $<0.001$ \\
\hline $0.98-1.09$ & 3.3 & $1.38(1.17-1.62)$ & $<0.001$ & $1.41(1.19-1.66)$ & $<0.001$ \\
\hline$>1.09$ & 3.8 & $1.51(1.28-1.77)$ & $<0.001$ & $1.59(1.35-1.87)$ & $<0.001$ \\
\hline \multicolumn{6}{|c|}{ HDL-cholesterol (mmol/1) } \\
\hline$<0.92$ & 4.5 & 1 & & 1 & \\
\hline $0.92-1.06$ & 3.5 & $0.70(0.61-0.81)$ & $<0.001$ & $0.76(0.66-0.88)$ & $<0.001$ \\
\hline $1.07-1.24$ & 2.8 & $0.59(0.51-0.68)$ & $<0.001$ & $0.70(0.60-0.82)$ & $<0.001$ \\
\hline$>1.24$ & 2.4 & $0.50(0.43-0.59)$ & $<0.001$ & $0.66(0.56-0.79)$ & $<0.001$ \\
\hline \multicolumn{6}{|l|}{ ApoA-I (g/l) } \\
\hline$<1.15$ & 4.3 & 1 & & 1 & \\
\hline $1.15-1.27$ & 3.6 & $0.76(0.66-0.87)$ & $<0.001$ & $0.84(0.73-0.97)$ & 0.02 \\
\hline $1.28-1.41$ & 3.1 & $0.73(0.63-0.85)$ & $<0.001$ & $0.88(0.76-1.03)$ & 0.11 \\
\hline$>1.41$ & 2.2 & $0.50(0.43-0.59)$ & $<0.001$ & $0.69(0.58-0.83)$ & $<0.001$ \\
\hline \multicolumn{6}{|l|}{ ApoA-II (g/l) } \\
\hline$<0.30$ & 3.2 & 1 & & 1 & \\
\hline $0.30-0.34$ & 4.4 & $0.87(0.75-1.00)$ & 0.06 & $0.93(0.81-1.08)$ & 0.37 \\
\hline $0.35-0.39$ & 3.3 & $0.77(0.66-0.90)$ & 0.001 & $0.89(0.76-1.05)$ & 0.16 \\
\hline$>0.39$ & 2.3 & $0.61(0.52-0.73)$ & $<0.001$ & $0.78(0.65-0.93)$ & 0.006 \\
\hline \multicolumn{6}{|c|}{ Lipid and lipoprotein ratios } \\
\hline \multicolumn{6}{|c|}{ Total cholesterol:HDL-cholesterol } \\
\hline$<4.04$ & 2.2 & 1 & & 1 & \\
\hline $4.04-4.71$ & 2.9 & $1.34(1.12-1.59)$ & 0.001 & $1.27(1.07-1.52)$ & 0.008 \\
\hline $4.72-5.49$ & 3.1 & $1.43(1.20-1.70)$ & $<0.001$ & $1.30(1.09-1.55)$ & 0.004 \\
\hline$>5.49$ & 4.9 & $2.34(1.99-2.74)$ & $<0.001$ & $1.98(1.67-2.34)$ & $<0.001$ \\
\hline
\end{tabular}


Table 4 (continued)

\begin{tabular}{|c|c|c|c|c|c|}
\hline \multirow[t]{2}{*}{ Variables in ranges } & \multirow[t]{2}{*}{ CVD event rate } & \multicolumn{2}{|l|}{ Unadjusted } & \multicolumn{2}{|l|}{ Adjusted $^{\mathrm{a}}$} \\
\hline & & $\operatorname{HR}(95 \% \mathrm{CI})$ & $p$ value & $\operatorname{HR}(95 \% \mathrm{CI})$ & $p$ value \\
\hline \multicolumn{6}{|l|}{ Non-HDL:HDL } \\
\hline$<3.03$ & 2.2 & 1 & & 1 & \\
\hline $3.03-3.71$ & 2.9 & $1.31(1.10-1.56)$ & 0.003 & $1.23(1.03-1.47)$ & 0.02 \\
\hline $3.72-4.48$ & 3.2 & $1.48(1.24-1.75)$ & $<0.001$ & $1.35(1.13-1.61)$ & $<0.001$ \\
\hline$>4.48$ & 4.9 & $2.30(1.96-2.70)$ & $<0.001$ & $1.95(1.65-2.31)$ & $<0.001$ \\
\hline \multicolumn{6}{|c|}{ LDL-cholesterol:HDL-cholesterol } \\
\hline$<2.36$ & 2.3 & 1 & & 1 & \\
\hline $2.36-2.88$ & 2.9 & $1.27(1.07-1.51)$ & 0.007 & $1.22(1.02-1.45)$ & 0.03 \\
\hline $2.89-3.44$ & 3.3 & $1.44(1.22-1.71)$ & $<0.001$ & $1.28(1.07-1.52)$ & 0.006 \\
\hline$>3.44$ & 4.6 & $2.07(1.77-2.43)$ & $<0.001$ & $1.77(1.50-2.09)$ & $<0.001$ \\
\hline \multicolumn{6}{|l|}{ ApoB:ApoA-I } \\
\hline$<0.65$ & 2.2 & 1 & & 1 & \\
\hline $0.65-0.76$ & 3.0 & $1.35(1.13-1.61)$ & $<0.001$ & $1.26(1.06-1.51)$ & 0.01 \\
\hline $0.77-0.88$ & 3.6 & $1.66(1.40-1.96)$ & $<0.001$ & $1.45(1.22-1.72)$ & $<0.001$ \\
\hline$>0.88$ & 4.5 & $2.16(1.84-2.55)$ & $<0.001$ & $1.83(1.55-2.17)$ & $<0.001$ \\
\hline
\end{tabular}

$\overline{{ }^{a}}$ Adjusted for treatment group, sex, age, prior myocardial infarction, prior coronary artery bypass grafting, smoking, creatinine concentration, insulin use, $\mathrm{HbA}_{1 \mathrm{c}}$ and country of residence

${ }^{\mathrm{b}}$ Additionally adjusted for HDL-cholesterol

HDL-cholesterol and ApoB:ApoA-I ratios in non-diabetic and diabetic participants [36]. Collectively, these results provide little support for replacing measurement of non-HDLcholesterol and HDL-cholesterol and their ratio by measurement of the ApoB:ApoA-I ratio in people with diabetes.

Baseline values of HDL-cholesterol, ApoA-I and ApoB all individually significantly predicted cardiovascular outcome in the placebo and fenofibrate groups. Surprisingly, in contrast to the baseline level of ApoB, the baseline concentration of LDL-cholesterol was a significant predictor only in the fenofibrate group. The failure of LDL-cholesterol to predict outcomes in the placebo group may reflect the fact that when LDL particle size is small (as in type 2 diabetes), the concentration of LDL-cholesterol (in contrast to ApoB) is a poor indication of LDL particle concentration or total concentration of atherogenic lipoproteins. Since fenofibrate will probably have reduced the concentration of TRLs and also increased LDL particle size, the baseline LDL concentration in the fenofibrate group may have remained more reflective of the atherogenic lipoprotein particle concentration over the course of the study than would have been the case in the placebo group.

In this analysis of people with type 2 diabetes, the baseline concentration of ApoA-II (as a single variable) predicted future cardiovascular events in the fenofibrate group. However, the HR for ApoA-II in the placebo group, while similar to that in the fenofibrate group, did not reach statistical significance, although there was no evidence of heterogeneity by treatment of the effect.

The observation that treatment with fenofibrate increased the concentration of ApoA-II by nearly 30\% raises the possibility that a proportion of the reduction in cardiovascular events in the treated group may have been the consequence of the increase in ApoA-II. A robust increase in ApoA-II concentration in people treated with fenofibrate has been reported in several studies in addition to FIELD [45-47]. To the best of our knowledge, this analysis of the FIELD study is the first to suggest that ApoA-II may have protective properties in people with diabetes. This finding extends that reported by Birjmohun et al., who found that higher levels of ApoA-II were associated with a lower risk of future coronary artery disease in the European Prospective Investigation of Cancer-Norfolk cohort [48]. It should, however, be emphasised that our study provides no clues to potential mechanisms underlying this association.

A strength of the present study is that our cohort consisted of 9,795 people with diabetes. It used ApoB and ApoB:ApoA-I ratios as CVD risk markers, which has been most strongly advocated for people who have diabetes and the atherogenic triad, with elevation of ApoB [11, 22, 33]. It should be noted that our samples were collected from fasting patients. This may partly mask any predictive power of non-fasting triacylglycerol levels, which perform better than fasting values as risk predictors [36, 49, 50]. However, 
both non-HDL-cholesterol and ApoB would be expected to capture the additional risk of non-fasting triacylglycerol.

In conclusion, our analysis of 9,795 people with type 2 diabetes in the FIELD study cohort showed that baseline lipid and apolipoprotein ratios performed better than any single lipid or apolipoprotein in predicting CVD risk. Our findings also confirmed that HRs for traditional lipid ratios were as strong as those for the ApoB:ApoA-I ratio in this cohort of type 2 diabetic patients. Thus, these analyses provide little support for replacing traditional lipids and their ratios with measures of ApoB and ApoA-I, and their ratio, either as risk prediction tools or as a potential means to monitor the effects of lipid management. This information is important for clinical practice, as measurements of lipid ratios can be calculated from traditional lipid measures familiar to most clinicians.

Acknowledgements Fournier Pharma (now part of Abbott Pharmaceuticals) sponsored the FIELD trial but had no role in data collection or analysis. The authors acknowledge R. Pike for manuscript editing and A.-S. Veillard for assistance with statistical analysis. Both are from the National Health and Medical Research Council Clinical Trials Centre, University of Sydney, Sydney, Australia, and were uncompensated.

Duality of interest M.-R. Taskinen has received honoraria from Merck Sharpe \& Dohme, Novartis, Sanofi-Aventis and Kowa, and has been an advisory board member for Merck Sharpe \& Dohme and Merck/Schering-Plough. P. Barter has received research support from Pfizer and Merck Sharpe \& Dohme, and honoraria from Abbott, Bristol Myers Squibb, Roche, Sanofi-Aventis, Astra Zeneca, Pfizer and Merck Sharpe \& Dohme, and has been on advisory boards of Astra Zeneca, Roche, Pfizer and Merck Sharpe \& Dohme. C. Ehnholm has received honoraria from the pharmaceutical industry. D. Sullivan has received honoraria from and been an advisory board member for Solvay Pharmaceuticals, AstraZeneca, Merck Sharpe \& Dohme, Pfizer and Schering Plough. R. J. Simes has received an honorarium from Solvay. A. C. Keech has received honoraria from the pharmaceutical industry, has been on several pharmaceutical advisory boards and has acted as an expert witness for Medicines Australia. All other authors declare that there is no duality of interest associated with this manuscript.

\section{References}

1. Taskinen MR (2005) Type 2 diabetes as a lipid disorder. Curr Mol Med 5:297-308

2. Mooradian AD (2009) Dyslipidemia in type 2 diabetes mellitus. Nat Clin Pract Endocrinol Metab 5:150-159

3. Cromwell WC, Otvos JD, Keyes MJ et al (2007) LDL particle number and risk of future cardiovascular disease in the Framingham offspring study - implications for LDL management. J Clin Lipidol 1:583-592

4. Blake GJ, Otvos JD, Rifai N, Ridker PM (2002) Low-density lipoprotein particle concentration and size as determined by nuclear magnetic resonance spectroscopy as predictors of cardiovascular disease in woman. Circulation 106:1930-1937

5. Otvos JD, Collins D, Freedman DS et al (2006) Low-density lipoprotein and high-density lipoprotein particle subclasses predict coronary events and are favorably changed by gemfibrozil therapy in the Veterans Affairs High-Density Lipoprotein Intervention Trial. Circulation 113:1556-1563

6. El Harchaoui K, van der Steeg WA, Stroes ES et al (2007) Value of low-density lipoprotein particle number and size as predictors of coronary artery disease in apparently healthy men and women: the EPIC-Norfolk prospective population study. J Am Coll Cardiol 49:547-553

7. Sniderman A (2009) Targets for LDL-lowering therapy. Curr Opin Lipidol 20:282-287

8. Lau JF, Smith DA (2009) Advanced lipoprotein testing: recommendations based on current evidence. Endocrinol Metab Clin North Am 38:1-31

9. Contois JH, McConnell JP, Sethi AA et al (2009) Apolipoprotein $\mathrm{B}$ and cardiovascular disease risk: position statement from the AACC Lipoproteins and Vascular Diseases Division Working Group on Best Practices. Clin Chem 55:407-419

10. Barter PJ, Ballantyne CM, Carmena R et al (2006) Apo B versus cholesterol in estimating cardiovascular risk and in guiding therapy: report of the thirty-person/ten-country panel. J Intern Med 259:247-258

11. Sniderman AD (2010) Apolipoprotein B, diabetes and medical consensus. Ann Clin Biochem 47:2-3

12. Miller M, Ginsberg HN, Schaefer EJ (2008) Relative atherogenicity and predictive value of non-high-density lipoprotein cholesterol for coronary heart disease. Am J Cardiol 101:10031008

13. Robinson JG, Wang S, Smith BJ, Jacobson TA (2009) Metaanalysis of the relationship between non-high-density lipoprotein cholesterol reduction and coronary heart disease risk. J Am Coll Cardiol 53:316-322

14. Rosenson RS (2009) Management of non-high-density lipoprotein abnormalities. Atherosclerosis 207:328-335

15. Lu W, Resnick HE, Jablonski KA et al (2003) Non-HDL cholesterol as a predictor of cardiovascular disease in type 2 diabetes: the strong heart study. Diabetes Care 26:16-23

16. Jiang R, Schulze MB, Li T et al (2004) Non-HDL cholesterol and apolipoprotein B predict cardiovascular disease events among men with type 2 diabetes. Diabetes Care 27:1991-1997

17. Brunzell JD, Davidson M, Furberg CD, American Diabetes Association, American College of Cardiology Foundation et al (2008) Lipoprotein management in patients with cardiometabolic risk: consensus statement from the American Diabetes Association and the American College of Cardiology Foundation. Diabetes Care 31:811-822

18. No authors listed (2009) Executive summary: standards of medical care in diabetes-2009. Diabetes Care 32(Suppl 1):S6S12

19. Genest J, McPherson R, Frohlich J et al (2009) 2009 Canadian Cardiovascular Society/Canadian guidelines for the diagnosis and treatment of dyslipidemia and prevention of cardiovascular disease in the adult -2009 recommendations. Can J Cardiol 25:567-579

20. Grundy SM, Cleeman JI, Merz CN, Coordinating Committee of the National Cholesterol Education Program et al (2004) Implications of recent clinical trials for the National Cholesterol Education Program Adult Treatment Panel III guidelines. Arterioscler Thromb Vasc Biol 24:e149-e161

21. Blaha M, Blumenthal R, Brinton E, Jacobson T (2008) The importance of non-HDL cholesterol reporting in lipid management. J Clin Lipidol 2:267-273

22. Chan DC, Watts GF (2006) Apolipoproteins as markers and managers of coronary risk. QJM 99:277-287

23. Denke MA (2005) Weighing in before the fight: low-density lipoprotein cholesterol and non-high-density lipoprotein cholesterol versus apolipoprotein $\mathrm{B}$ as the best predictor for coronary 
heart disease and the best measure of therapy. Circulation 112:336-337

24. Kastelein JJ, van der Steeg WA, Holme I, NT Study Group, IDEAL Study Group et al (2008) Lipids, apolipoproteins, and their ratios in relation to cardiovascular events with statin treatment. Circulation 117:3002-3009

25. Barter PJ, Rye KA (2006) The rationale for using apoA-I as a clinical marker of cardiovascular risk. J Intern Med 259:447-454

26. Thompson A, Danesh J (2006) Associations between apolipoprotein $\mathrm{B}$, apolipoprotein $\mathrm{AI}$, the apolipoprotein $\mathrm{B} / \mathrm{AI}$ ratio and coronary heart disease: a literature-based meta-analysis of prospective studies. J Intern Med 259:481-492

27. Lind L (2008) Apolipoprotein B/A1 and risk of cardiovascular disease. Lancet 372:185-186

28. Sulkes D, Brown BG, Krauss RM, Segrest JP, Sniderman AD, Roberts WC (2008) The editor's roundtable: expanded versus standard lipid panels in assessing and managing cardiovascular risk. Am J Cardiol 101:828-842

29. Charlton-Menys V, Durrington P (2006) Apolipoproteins AI and $\mathrm{B}$ as therapeutic targets. J Intern Med 259:462-472

30. Walldius G, Jungner I, Holme I, Aastveit AH, Kolar W, Steiner E (2001) High apolipoprotein B, low apolipoprotein A-I, and improvement in the prediction of fatal myocardial infarction (AMORIS study): a prospective study. Lancet 358:2026-2033

31. McQueen MJ, Hawken S, Wang X, INTERHEART study investigators et al (2008) Lipids, lipoproteins, and apolipoproteins as risk markers of myocardial infarction in 52 countries (the INTERHEART study): a case-control study. Lancet 372:224-233

32. Holme I, Cater NB, Faergeman O, Incremental Decrease in Endpoints Through Aggressive Lipid-Lowering (IDEAL) Study Group et al (2008) Lipoprotein predictors of cardiovascular events in statin-treated patients with coronary heart disease. Insights from the Incremental Decrease in End-points Through Aggressive Lipid-lowering Trial (IDEAL). Ann Med 40:456-464

33. Sniderman AD (2007) Low-density lipoprotein lowering in type 2 diabetes mellitus: how to know how low to go. Curr Opin Endocrinol Diabetes Obes 14:116-123

34. Sniderman AD, Faraj M (2007) Apolipoprotein B, apolipoprotein A-I, insulin resistance and the metabolic syndrome. Curr Opin Lipidol 18:633-637

35. Davidson MH (2008) Is LDL-C passed its prime? The emerging role of non-HDL, LDL-P, and ApoB in CHD risk assessment. Arterioscler Thromb Vasc Biol 28:1582-1583

36. Emerging Risk Factors Collaboration, Di Angelantonio E, Sarwar N, Perry P et al (2009) Major lipids, apolipoproteins, and risk of vascular disease. JAMA 302:1993-2000

37. Charlton-Menys V, Betteridge DJ, Colhoun H et al (2009) Apolipoproteins, cardiovascular risk and statin response in type 2 diabetes: the Collaborative Atorvastatin Diabetes Study (CARDS). Diabetologia 52:218-225
38. FIELD study Investigators (2005) Effects of long-term fenofibrate therapy on cardiovascular events in 9795 people with type 2 diabetes mellitus (the FIELD study): randomised controlled trial. Lancet 366:1849-1861

39. Hanley JA, McNeil BJ (1982) The meaning and use of the area under a receiver operating characteristic (ROC) curve. Radiology 143:29-36

40. van der Steeg WA, Boekholdt SM, Stein EA et al (2007) Role of the apolipoprotein B-apolipoprotein A-I ratio in cardiovascular risk assessment: a case-control analysis in EPIC-Norfolk. Ann Intern Med 146:640-648

41. Ingelsson E, Schaefer EJ, Contois JH et al (2007) Clinical utility of different lipid measures for prediction of coronary heart disease in men and women. JAMA 298:776-785

42. Ray KK, Cannon CP, Cairns R, Morrow DA, Ridker PM, Braunwald E (2009) Prognostic utility of apoB/AI, total cholesterol/HDL, non-HDL cholesterol, or hs-CRP as predictors of clinical risk in patients receiving statin therapy after acute coronary syndromes: results from PROVE IT-TIMI 22. Arterioscler Thromb Vasc Biol 29:424-430

43. Scott R, O'Brien R, Fulcher G, Fenofibrate Intervention and Event Lowering in Diabetes Study Investigators et al (2009) Effects of fenofibrate treatment on cardiovascular disease risk in 9795 individuals with type 2 diabetes and various components of the metabolic syndrome: the Fenofibrate Intervention and Event Lowering in Diabetes (FIELD) study. Diabetes Care 32:493-498

44. ACCORD Study Group (2010) Effects of combination lipid therapy in type 2 diabetes mellitus. N Engl J Med 362:1563-1574

45. Keeting GM, Croom KF (2007) Fenofibrate: a review of its use in primary dyslipidaemia, the metabolic syndrome and type 2 diabetes mellitus. Drugs 67:121-153

46. Després JP, Lemieux I, Salomon H, Delaval D (2002) Effects of micronized fenofibrate versus atorvastatin in the treatment of dyslipidaemic patients with low plasma HDL-cholesterol levels: a 12-week randomized trial. J Intern Med 251:490-499

47. Bard JM, Parra HJ, Camare R et al (1992) A multicenter comparison of the effects of simvastatin and fenofibrate therapy in severe primary hypercholesterolemia, with particular emphasis on lipoproteins defined by their apolipoprotein composition. Metabolism 41:498-503

48. Birjmohun RS, Dallinga-Thie GM, Kuivenhoven JA et al (2007) Apolipoprotein A-II is associated with risk of future coronary artery disease. Circulation 116:2029-2035

49. Langsted A, Freiberg JJ, Nordestgaard BG (2008) Fasting and nonfasting lipid levels influence of normal food intake on lipids, lipoproteins, apolipoproteins, and cardiovascular risk prediction. Circulation 118:2047-2056

50. Nordestgaard BG, Benn M, Schnohr P, Tybjaerg-Hansen A (2007) Nonfasting triglycerides and risk of myocardial infarction, ischemic heart disease, and death in men and women. JAMA 298:299-308 